\title{
Placental Villous Stromal Hemorrhage
}

National Cancer Institute

\section{Source}

National Cancer Institute. Placental Villous Stromal Hemorrhage. NCI Thesaurus. Code C118153.

Extravascular blood in the chorionic villi. 